\title{
Journal of Pharmaceutical and Pharmacological Sciences
}

Hajare R. J Pharma Pharma Sci: JPPS-135.

\section{Self-Study of Transference and Health Effects on the Senior Citi- zens Who Not Having Children, Measures Need to be Put in Place to Fill the Care Gap in Pune Areas Suburban Hospitals and Nurs- ing Homes: An Exploratory Report}

\author{
Rahul Hajare ${ }^{1,2^{*}}$ \\ ${ }^{1}$ Department of Quality Assurance, Rajgad Dnyanpeeth's College of Pharmacy, India \\ ${ }^{2}$ Indian Council of Medical Research, Department of Health Research, India
}

*Corresponding author: Rahul Hajare, Department of Quality Assurance, Rajgad Dnyanpeeth's College of Pharmacy, Indian Council of Medical Research Department of Health Research Government of India. Former Post-Doctoral Fellow, India. Tel: +919765704048; Email: rahulhajare@rediffmail.com

Citation: Hajare R (2017) Self-Study of Transference and Health Effects on the Senior Citizens Who Not Having Children, Measures Need to be Put in Place to Fill the Care Gap in Pune Areas Suburban Hospitals and Nursing Homes: An Exploratory Report. J Pharma Pharma Sci: JPPS-135. DOI:10.29011/2574-7711/100035

Received Date: 15 July, 2017; Accepted Date: 30 July, 2017; Published Date: 07 August, 2017

\begin{abstract}
In 1986 WHO (World Health Organisation) formed the global programme committee. Committee adopted a concept of district health system, which has based on primary healthcare and has a part of our national health policy. Now it has complex institutions dealing with not only patient care but also involved in research and development and professional education. Their main objective has to provide high quality health care. It has unique places where patients of senior citizens interact with physician and caregiver. In fact, observation have been made by the health team expands caregiver should also begin to monitor the senior citizen's patients. Also, this study shows expansion of the clinical stage in which much of care and greatest concentration of professional skill should be needed for monitor health problems and whose diseases have prevented and detected early stage.
\end{abstract}

Keywords: End-of-Life Care; Relocation of Dying Patients; Senior Citizens

\section{Introduction}

We report here the effects of transference senior citizen's patients from Pune suburban areas hospitals were evaluated. Relocation senior citizen's patients have reported for the first time from Indian hospitals, especially from developed cities in India. Researcher interest in the clinical consequences of relative deficiency identified in the aging male caring is well served by the series of papers from the society in the past issue of the Journal of Palliative Care \& Medicine. In 2016 about 80\% of all Indians died in hospitals and nursing homes. This shows the outstanding importance of inpatient care in end of life caring. A first, study in 2015 provided indications that the patient's last phase of life leads to relocation. And this, although it is the goal of all caregivers to recognize the dying as such, because relocation basically means a situation involving exposure to lose interest care in all kind $[1,2]$.

\section{Objectives}

This article provides an overview of detail information of analyte about the transfer of senior citizen's persons and it has use in the management of certain disease states in an emergency setting.

\section{Method}

In order to overcome this information deficiency, a different constituting a typical representative sample of a larger group 


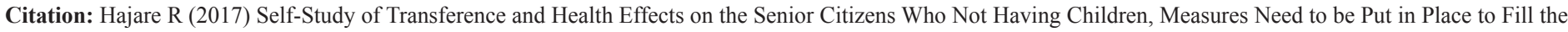
Care Gap in Pune Areas Suburban Hospitals and Nursing Homes: An Exploratory Report. J Pharma Pharma Sci: JPPS-135.

question-wide questionnaire was developed $[3,4]$ and questioned to hospital staffs from hospitals and nursing homes in 2016 (Pune suburban areas hospitals). The questionnaire determines the frequency of transference, the time, place, the address of the transference and the influencing factors which justify the transfers. The questionnaire has answered particularly by nurses and doctors. The questionnaire has answered only in writing procedure. As far as possible and meaningful, the data of the total of 545 interviewees were clustered so that each hospital has included as an average case in the 1 evaluation. In this way, 10 hospitals and 6 nursing homes of different sizes were included in the evaluation. The study has a relating character. The results should be reviewed by available supply data and further studies should be supplemented [5].

\section{Results}

The following central findings were found: In approximately $43 \%$ of the hospitals and approx. $50 \%$ of the inpatient nursing homes there have been transfers of senior citizen's people. Nursing homes transfer senior citizen's patients primarily to hospitals and only in very few cases in a home. Hospitals' employees state that most of their transfers have carried out within their chain hospital. In some cases, the relocation to a hospice takes place in a few homes. In the study, no clear data of the day of the week or of the time could be identified. Physico-care impairments such as dyspnoea, painful conditions or the deterioration of the general condition, can be listed as the central reasons for relocations. In contrast, mental reasons such as anxiety, confusion, or depressive mood have also more important. Both the achieved quality of the family integration as well as the cooperation with the family doctor has an impact on a possible relocation behaviour of the institutions. The better they succeed, the lower the relocation. Written patient interventions have a medium to distinct influence. The relocation behaviour in the hospitals differs from that of the nursing homes. The nursing facilities have much less prepared for physical deterioration. The influence of the family doctor, the relatives and the patient has also lower in the hospitals. Basically, existing personal shortcomings have regarded as more problematic for the relocation behaviour, as acute personal shortcomings. This assessment unites the employees. In open questions, respondents were given the opportunity to provide information on how to avoid relocation. The following refence has formulated: forward looking planning to further develop home care, to improve cooperation with hospices and specialized palliative services, to improve the medical attitude, to increase the number and efficacy of patient care, better medical education, prevention of inappropriate use of intensive care, better and earlier counselling of relatives and patients, adaptation of premises, binding establishment of ethics, gratitude and most important is love.

\section{Conclusion}

For nursing homes, they have even better placed to deal with the deterioration of their patients, so that senior citizens people have not identified as "Critical Condition", with all the problematic consequences. In the hospitals is quite similar. Here, too, the general units of care must be supported in such a way that senior citizen's persons have not yet moved into monitoring units as ICM or IMC. It is hoped that with the introduction of a new law, the situation for senior citizen's people in the hospitals and nursing homes in India will continue to improve. This includes less relocation of senior citizen's patients. Researcher came out that, compared with patients who have reaming in hospitals; those relocated patients who were still alive at the time of follow up showed no evidence of changes in behavioural dependency or the number of problem behaviours. Moving patients and staff together may have helped to minimize the impact of the move on the patients, but this study draws attention to the importance of providing support for staff undergoing such changes. Clinical constraint for the role of caregiver and practitioner's choice in treatment of senior citizen's person remain inconclusive and requires validate randomized cohort studies to establish care regimens. This clearly indicates that the senior citizen's person in India needs close observation and check the progress of quality over a period of time. Hence these findings have extremely significant and need to be followed by larger and controlled studies. The paper has indeed generated discussion on this important advancement. I would like to request Hon'ble present prime minister to need of intervention of more important amendments for senior citizen's people especially not having children and implementation of new Act for hospitalize old patient for effective treatment and education for caregiver. A hospital has number criteria by which the hospital has been identified. It has unique place where patients of all age, especially senior citizens and background interact, with physician and nurses, administration has control the vigilance. Therefore, the organisational structure depends upon the activities going around the patient health. It has need to intervene the legal status to the hospitals, which is the form of society, trust or self-finance and governing body will overall responsible for the improper function of the hospital and the services render to the senior citizen's patient. Also, executive director or a chair person will be appointed as an administrator, through the basic test of clinical departments and has interest towards the senior citizen's care.

\section{Acknowledgments}

This study report work has supported under the unparallel supervision and guidance of Hon'ble Dr. Ramesh S. Paranjape (Former Director \& Renowned Scientist National AIDS Research 


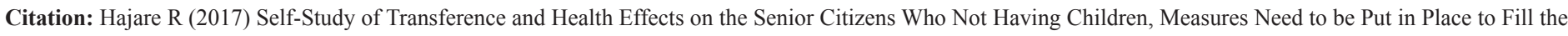
Care Gap in Pune Areas Suburban Hospitals and Nursing Homes: An Exploratory Report. J Pharma Pharma Sci: JPPS-135.

Institute, Pune). I express my sincere gratitude towards him for motivation and being great knowledge source for this work.

\section{References}

1. Ambastha AKA (2017) Study of Health and Functionality of the Oldest Old in a Tertiary Health Care Setting. MD Thesis. New Delhi: All India Institute of Medical sciences.

2. Rajan S, Kurusiu V, Sunitha S (2014) Demography of Aging in India. In Textbook of Geriatric Medicine, P. Sanchetee, ed. Hyderabad: Paras Medical Publishers 6-18.
3. Indian Council of Medical Research (ICMR). Determinants of Functional Status of Older Indians 2005- 2007 Task Force Project, New Delhi.

4. Health Emergencies in Older People: Predictors of hospital revisit and adverse outcome 2009-2012. Ad hoc Project, New Delhi.

5. George WM (2016) New Seal of Quality as a Result of Empirical Studies: Palliative-friendly Hospital and Palliative-friendly Residential Care Facility, Journal of Palliative Care \& Medicine. 